\title{
Patterns and predictors of malaria care-seeking, diagnostic testing, and artemisinin-based combination therapy for children under five with fever in Northern Nigeria: a cross-sectional study
}

\author{
Kathryn R Millar ${ }^{1 *}$, Jennifer McCutcheon ${ }^{1 *}$, Eugenie H Coakley ${ }^{1}$, William Brieger ${ }^{2}$, Mohammed A Ibrahim³ $^{3}$
} Zainab Mohammed ${ }^{3}$, Amos Bassi ${ }^{3}$ and William Sambisa ${ }^{3}$

\begin{abstract}
Background: Despite recent improvements in malaria prevention strategies, malaria case management remains a weakness in Northern Nigeria, which is underserved and suffers the country's highest rates of under-five child mortality. Understanding malaria care-seeking patterns and comparing case management outcomes to World Health Organization (WHO) and Nigeria's National Malaria Control Programme (NMCP) guidelines are necessary to identify where policy and programmatic strategies should focus to prevent malaria mortality and morbidity.

Methods: A cross-sectional survey based on lot quality assurance sampling was used to collect data on malaria care-seeking for children under five with fever in the last two weeks throughout Sokoto and Bauchi States. The survey assessed if the child received NMCP/WHO recommended case management: prompt treatment, a diagnostic blood test, and artemisinin-based combination therapy (ACT). Deviations from this pathway and location of treatment were also assessed. Lastly, logistic regression was used to assess predictors of seeking treatment.

Results: Overall, $76.7 \%$ of children were brought to treatment- $45.5 \%$ to a patent medicine vendor and $43.8 \%$ to a health facility. Of children brought to treatment, $61.5 \%$ sought treatment promptly, but only $9.8 \%$ received a diagnostic blood test and $7.2 \%$ received a prompt ACT. When assessing adherence to the complete case management pathway, only $1.0 \%$ of children received NMCP/WHO recommended treatment. When compared to other treatment locations, health facilities provided the greatest proportion of children with NMCP/WHO recommended treatment. Lastly, children 7-59 months old were at $1.74(p=0.003)$ greater odds of receiving treatment than children $\leq 6$ months.

Conclusions: Northern Nigeria's coverage rates of NMCP/WHO standard malaria case management for children under five with fever fall short of the NMCP goal of $80 \%$ coverage by 2010 and universal coverage thereafter. Given the ability to treat a child with malaria differs greatly between treatment locations, policy and logistics planning should address the shortages of essential malaria supplies in recommended and frequently accessed treatment locations. Particular emphasis should be placed on integrating the private sector into standardized care and educating caregivers on the necessity for testing before treatment and the availability of free ACT in public health facilities for uncomplicated malaria.
\end{abstract}

Keywords: Malaria, Care-seeking, Children under five, Nigeria, Artemisinin-based combination therapy, Diagnostic test

\footnotetext{
* Correspondence: katierae85@gmail.com; jmccutcheon@jsi.com

'JSI Research \& Training Institute, Inc., 44 Farnsworth Street, Boston, MA 02210, USA

Full list of author information is available at the end of the article
} 


\section{Background}

Malaria is a parasitic illness that affects millions around the world each year. The World Health Organization (WHO) estimates that in 2012 there were 207 million malaria cases and 627,000 malaria deaths globally; 77\% of these were in children under five years of age [1]. The majority of malaria deaths are amongst children in Africa, where malaria kills one child every minute [2]. In fact, malaria accounts for $7 \%$ of deaths in children under five globally [3].

Nigeria is particularly afflicted by this disease. Malaria is the leading cause of child mortality in the nation and accounts for $30 \%$ of hospitalizations, $60 \%$ of outpatient visits [4], and $30 \%$ of deaths among children under five [5]. In 2008, there were about 100 million suspected cases and 300,000 deaths due to malaria in Nigerian children under five [6].

When prevention fails, effective malaria case management is key for preventing morbidity and mortality for children under five. Three priority areas of malaria case management-as identified by the WHO in 2010 [7] and adopted by the Nigeria National Malaria Control Programme (NMCP) [8]-are (1) prompt care-seeking within the first 24 hours of symptoms; (2) performance of a parasitological blood test, by either microscopy or rapid diagnostic testing (RDT), to prevent over- and under-diagnosis of malaria; and (3) administration of artemisinin-based combination therapy (ACT) if the blood test is positive [7]. ACT has been designated as the first-line treatment for its ability to reduce drug resistance and its efficacy in treating malaria [7]. Prompt, accurate diagnosis and treatment of malaria is essential to prevent death since the majority of malaria deaths occur within the first 24 hours following onset of fever [5].

In Nigeria, ACT was introduced as first-line treatment in 2005 and RDTs were recommended for diagnosis in 2007. The NMCP strategy for 2009-2013 [9] set a goal target of $80 \%$ of malaria cases to be diagnosed with a blood test and treated with an ACT within the first 24 hours of fever onset [8] by 2010 and universal coverage thereafter, based on goals set by RBM [6].

Despite sound policies, goals, and improvements in prevention through increased coverage of insecticidetreated nets (ITNs) [10,11], malaria case management has continued to be inadequate in Nigeria due to weak health systems [12,13]. As of 2013, in Nigeria, $70.1 \%$ of children under five with fever sought advice or treatment, only $11.1 \%$ received a blood test, $6.0 \%$ received an ACT and $4.2 \%$ received an ACT within 24 hours of fever onset [11]. Also, 30.9\% of Nigerian children who sought treatment for malaria received chloroquine [11], a common anti-malarial, deemed ineffective in Nigeria due to resistance since the 1980s [14]. When stratified by geopolitical zone (GPZ), treatment rates were lowest in the
North West and North East GPZs with only 6.7\% and $8.7 \%$ receiving a blood test and $3.5 \%$ and $2.0 \%$ receiving an ACT within 24 hours of fever onset, respectively [11].

While regional data are helpful in identifying disparities generally, there is limited state-level data on malaria case management, or treatment, and patient care-seeking patterns. The 2013 Demographic and Health Survey for Nigeria details treatment received by state, but does not detail where children seek care and the treatment they receive there, by state [11]. However, this information is important and can help determine if $\mathrm{FMOH}$ goal coverage rates/NMCP strategies are being met, and inform policy and programme implementation by state MOHs, NGOs, and other organizations to improve case management [15]. Given the high burden of disease and poor health systems in these regions, this information is especially important.

To help address this paucity of information, a crosssectional study was conducted in two states in Northern Nigeria. The primary aim of the study was to describe the current care-seeking and treatment pattern for children under five with fever in Northern Nigeria. The secondary aims were to determine how many children with fever receive treatment consistent with $\mathrm{NMCP} / \mathrm{WHO}$ standards and which factors help predict if a child under five with fever is taken to treatment, none of which have been studied in Nigeria to date.

\section{Methods}

\section{Setting area and background}

Nigeria - the most populous country in Africa with 140 million people [16] - is comprised of six geopolitical zones (GPZs), 36 states, and 774 Local Government Areas (LGAs). Northern Nigeria is historically underserved and suffers the highest infant mortality rate (IMR) and under five mortality rate (U5MR) [11]: the North East and North West GPZs have an IMR of 77 and 89 per 1,000 live births [11] and a U5MR of 160 and 185 per 1,000 live births [11], respectively. This is higher than the national IMR of 69 per 1,000 live births and U5MR of 128 per 1,000 live births [11].

In order to address these regional disparities, the Targeted States High Impact Project (TSHIP) - a fiveyear reproductive, maternal, newborn and child health and family planning (RMNCH/FP) program-was implemented in Bauchi, a state with a population of 4.6 million in the North East GPZ, and Sokoto, a state with a population of 3.7 million in the North West GPZ [16]. TSHIP-implemented by JSI Research and Training Institute, Inc. from 2009 through 2015-was the first United States Agency for International Development (USAID) full-state approach to providing $\mathrm{RMNCH} / \mathrm{FP}$ services in Nigeria. This approach addressed the challenges of effective donor collaboration, program efficacy, and health systems strengthening. Malaria interventions, 
especially for pregnant women and children under five, were implemented in these states through TSHIP. Bauchi and Sokoto experience the highest transmission of malaria from April to October.

In order to contextualize malaria care-seeking, understanding the structure of the Nigerian health care system is necessary, as well. In the public sector there are dispensaries, primary health facilities (e.g., Primary Health Clinics [PHCs]), secondary facilities, and tertiary hospitals [8]. The private sector is made up of patent medicine vendors (PMVs), private clinics and hospitals. The Ministry of Health $(\mathrm{MOH})$ is responsible for providing operational supervision to the private sector to ensure compliance standards. However, enforcing these standards is difficult due to inadequate numbers of qualified personnel to carry out this task [17].

Despite poor regulation and standards of care, the largest source of treatment for children (and adults) with fever is PMVs (45.6\%) and the second largest are government health facilities (33.8\%) [11]. This is alarming due to the fact that PMV staff lack formal training and supervision [17] and serve a large proportion of patients.

In addition to high mortality rates and poor service delivery, commodity management is also poor in this region. Drug supply management has been an on-going problem, especially at the PHC level [13]. A stock-out analysis of ACTs and RDTs done by TSHIP in Sokoto showed a deficit of 2 million ACT doses and 700 thousand RDTs to meet the current malaria burden [18]. Thus, data to help identify patterns in care-seeking will allow us to inform programmatic and policy activities to strengthen malaria case management and to better serve rural and underserved populations.

\section{Study design and implementation}

In November and December 2012, a relatively low period of malaria transmission, a cross-sectional lot quality assurance sampling (LQAS) survey was administered proportionally throughout each of the 20 LGAs in Bauchi and 23 LGAs in Sokoto (Figure 1 [19]). This was the baseline survey of an annual survey for monitoring and evaluation for TSHIP.

LQAS originated in the manufacturing sector to test the quality of a lot of goods. However, several studies and health programmes have used LQAS as a methodology to assess programme coverage and performance indicators in public health $[5,20]$. This method of sampling divides a programme area into smaller geographic "lots," or supervision areas, and then samples households from each lot. The results are then compared with a decision rule, or benchmark value, to help local TSHIP planners identify areas that are meeting or failing the benchmark value. This ability to prioritize the most vulnerable areas is crucial when resources are limited.

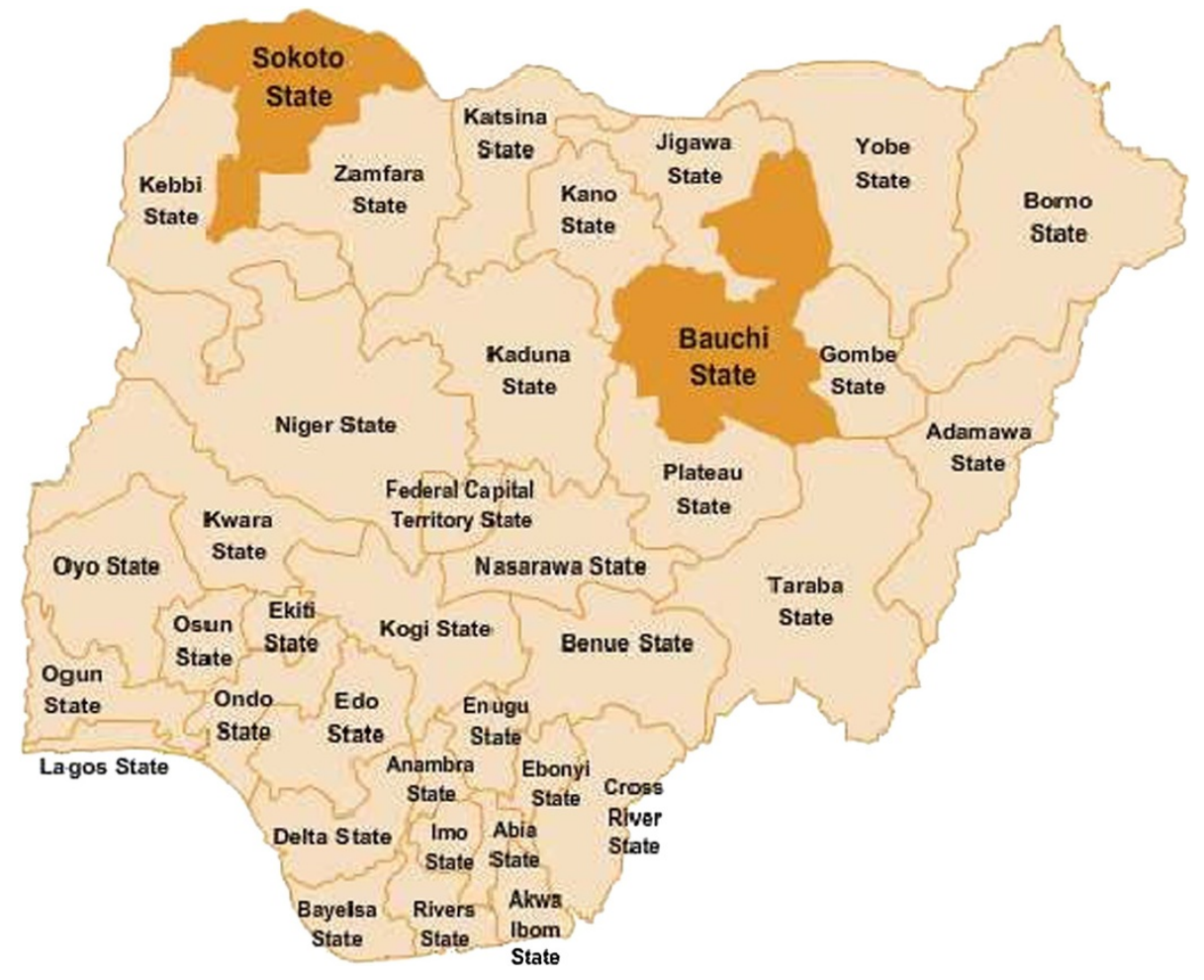

Figure 1 Map of Nigeria: Bauchi and Sokoto highlighted. 
Nine separate questionnaires were implemented as part of the LQAS survey, which covered topics on maternal, newborn, and child health; malaria; and family planning to assess TSHIP's programmatic activity. The data from "Questionnaire 8: Mothers of children 0 to 59 months with fever in the last 2 weeks" as well as "Questionnaire 1: Women of reproductive age with children aged 0 to 59 months" are used in this paper.

In Bauchi and Sokoto, each LGA acted as a lot or a supervision area. Within each lot, 19 settlements (villages) were randomly selected, proportional to population and representative of each LGA, to complete one comprehensive LQAS survey. LQAS methodology is based on a decision rule of choosing 12-30 settlements per lot. Nineteen settlements per lot have been proven to give a good fit for an annual coverage target of $50 \%$ or below with a sensitivity of $95 \%$ [21]. A household in each settlement was randomly selected and all applicable questionnaires were completed. If a selected household was not eligible to answer all nine questionnaires, the surveyor moved on to the next household to finish the remaining questionnaires. This approach, called "parallel sampling", is unique to LQAS. If a settlement was too small to complete all nine questionnaires, a neighboring settlement was visited to complete the survey.

In a household where two or more eligible respondents were found, one respondent was randomly selected. Interviewers were trained on the LQAS methodology and use of the pre-tested tools over a period of five days. Questionnaire 1 contained detailed maternal demographic questions. The questionnaire (number 8 ) on malaria included questions about maternal and child's age, whether treatment was sought outside of the home, promptness of treatment, location of treatment, whether the child received a diagnostic test (either microscopy or RDT), whether the child took a medication, and what type of medication the child took.

In this analysis, we combine all of the small samples to create an unbiased random sample of 814 households representing the states of Bauchi $(n=379)$ and Sokoto $(n=435)$. With this much larger sample size, there is more power to describe care-seeking and treatment patterns, and identify differences between the two states. Using the chi-square test, a 5\% significance level, and the given sample sizes, there is $80-90 \%$ power to identify a $10 \%$ or greater difference between the states across the range of possible response percentages. Moreover, percentages reported for an individual state, or both states combined, have margins of error ranging from $2-5 \%$.

\section{Participants}

Both the first and malaria questionnaires included women of reproductive age (15-49 years old) with children aged 0-59 months. The malaria questionnaire only included children who had a fever in the last two weeks. Detailed descriptive and demographic information is reported from the first questionnaire, since it was not collected on the malaria questionnaire. Some, but not all, mothers completed both questionnaires. Since both questionnaires focused on the same target population in the same villages the demographics should represent the women who completed the malaria questionnaire. Maternal and child age, and child's sex, which were ascertained on both questionnaires, were statistically similar between the two survey samples.

\section{Variables}

Prompt treatment was defined as treatment on either the same or following day (24 hours) of fever onset based on recommendations from the RBM Partnership [6]. In addition, if the mother said the child received treatment, but indicated location of treatment as home and provider as self, the child was re-categorized as not receiving treatment, since treatment was not sought outside of the home.

Treatment location was categorized into formal and informal sectors. Formal treatment locations included health facilities and private doctors. Informal treatment locations included PMVs, community based health volunteers (CBHV), traditional practitioners, and other. Included in the informal "other" category are unauthorized drug sellers, friends/relatives, and other.

\section{Statistical methods}

To assess the primary aim of defining current careseeking and treatment patterns for children under five with fever, frequencies of survey question responses were computed. Responses were also cross-classified by state, and the chi-square test was used to assess the statistical significance of geographic differences. To address a secondary aim of comparing these results to the NMCP/ WHO standard case management pathway, results were organized according to the standard and the number and percent of respondents meeting each component of the case management pathway was estimated. Epi Info version 7 [22] was used for data entry and data cleaning and Stata/IC 12.1 [23] was uses for data analysis.

To assess another secondary aim-identifying whether maternal age, child age and gender, and state help predict if a child under five with fever is taken to treatment-a binary logistic regression was performed with seeking treatment as the dependent variable. Akaike information criterion and likelihood ratio tests (LRTs) were used to assess the explanatory power of the model and identify factors that contributed significantly to each model.

\section{Ethical approval}

Ethical approval was granted by the Sokoto and Bauchi State Health Research Ethics Committee and by local leaders in the study area. Approval from the National Health Research and Ethics Committee is not required 
when a study is done in less than three states. Participants in the survey gave written consent before answering the questionnaire.

\section{Results}

\section{Respondent characteristics}

Table 1 showcases the descriptive statistics of the study population. Stratification of the data by state shows significant demographic differences between states $(\mathrm{p}<0.05)$. Therefore, further analyses were done with all data combined and stratified by state. Of the 818 women and children pairs that answered this survey, four were excluded because they did not meet age criteria. Therefore, 814 woman and child pairs were included in the analysis.

Mean maternal age was $26.1(15-48)$ years. The vast majority of mothers had no education $(79.8 \%, 650)$ and

Table 1 Socio-demographic characteristics of mothers and children under five with fever

\begin{tabular}{|c|c|c|c|c|c|c|c|}
\hline & \multicolumn{2}{|c|}{ Bauchi (N = 379) } & \multicolumn{2}{|c|}{ Sokoto $(N=435)$} & \multicolumn{2}{|c|}{ Total $(\mathrm{N}=814)$} & \multirow[t]{2}{*}{ P-value } \\
\hline & $\mathrm{N}$ & $\%$ & $\mathrm{~N}$ & $\%$ & $\mathrm{~N}$ & $\%$ & \\
\hline \multicolumn{8}{|c|}{ Mother's characteristics } \\
\hline \multicolumn{8}{|l|}{ Age } \\
\hline Mean age (SD) & \multicolumn{2}{|c|}{$25.2(6.3)$} & \multicolumn{2}{|c|}{$26.9(6.7)$} & \multicolumn{2}{|c|}{$26.1(6.6)$} & 0.0002 \\
\hline $15-19$ years & 58 & $15.3 \%$ & 59 & $13.6 \%$ & 117 & $14.4 \%$ & 0.003 \\
\hline $20-24$ years & 114 & $30.1 \%$ & 90 & $20.7 \%$ & 204 & $25.1 \%$ & \\
\hline $25-29$ years & 93 & $24.5 \%$ & 104 & $23.9 \%$ & 197 & $24.2 \%$ & \\
\hline $30-34$ years & 73 & $19.3 \%$ & 107 & $24.6 \%$ & 180 & $22.1 \%$ & \\
\hline $35-49$ years & 41 & $10.8 \%$ & 75 & $17.2 \%$ & 116 & $14.2 \%$ & \\
\hline \multicolumn{8}{|l|}{ Education $^{*}$} \\
\hline No education & 263 & $69.4 \%$ & 387 & $89.0 \%$ & 650 & $79.8 \%$ & 0.000 \\
\hline Primary education & 77 & $20.3 \%$ & 27 & $6.2 \%$ & 104 & $12.8 \%$ & \\
\hline Secondary education & 30 & $7.9 \%$ & 8 & $1.8 \%$ & 38 & $4.7 \%$ & \\
\hline Higher education & 9 & $2.4 \%$ & 5 & $1.2 \%$ & 14 & $1.7 \%$ & \\
\hline \multicolumn{8}{|l|}{ Religion } \\
\hline Muslim & 352 & $92.9 \%$ & 429 & $98.6 \%$ & 781 & $96.0 \%$ & 0.000 \\
\hline Catholic & 3 & $0.8 \%$ & 1 & $0.2 \%$ & 4 & $0.5 \%$ & \\
\hline Other christian & 22 & $5.8 \%$ & 2 & $0.5 \%$ & 24 & $3.0 \%$ & \\
\hline Traditionalist & 2 & $0.5 \%$ & 3 & $0.7 \%$ & 5 & $0.6 \%$ & \\
\hline \multicolumn{8}{|l|}{ Marital status } \\
\hline Married & 376 & $99.2 \%$ & 422 & $97.0 \%$ & 798 & $98.0 \%$ & 0.02 \\
\hline Not-married & 3 & $0.8 \%$ & 13 & $3.0 \%$ & 16 & $2.0 \%$ & \\
\hline \multicolumn{8}{|c|}{ Children's characteristics } \\
\hline \multicolumn{8}{|l|}{ Age } \\
\hline Mean (SD) & \multicolumn{2}{|c|}{$16.0(12.3)$} & \multicolumn{2}{|c|}{$17.9(13.0)$} & \multicolumn{2}{|c|}{$17.0(12.7)$} & 0.03 \\
\hline $0-6$ months & 93 & $24.5 \%$ & 92 & $21.2 \%$ & 185 & $22.7 \%$ & 0.008 \\
\hline $7-12$ months & 87 & $23.0 \%$ & 95 & $21.8 \%$ & 182 & $22.4 \%$ & \\
\hline 13-18 months & 79 & $20.8 \%$ & 61 & $14.0 \%$ & 140 & $17.2 \%$ & \\
\hline 19-24 months & 57 & $15.0 \%$ & 96 & $22.1 \%$ & 153 & $18.8 \%$ & \\
\hline 25-59 months & 63 & $16.6 \%$ & 91 & $20.9 \%$ & 154 & $18.9 \%$ & \\
\hline Sex & & & & & & & 0.7 \\
\hline Male & 199 & $52.5 \%$ & 234 & $53.8 \%$ & 433 & $53.2 \%$ & \\
\hline Female & 180 & $47.5 \%$ & 201 & $46.2 \%$ & 381 & $46.8 \%$ & \\
\hline \multicolumn{8}{|c|}{ Household characteristics } \\
\hline Multifamily household & 34 & $9.0 \%$ & 95 & $21.8 \%$ & 129 & $15.8 \%$ & $<0.0001$ \\
\hline
\end{tabular}

Bold values are significant at a $\mathrm{p}<0.05$ level.

${ }^{*}$ Eight missing values for education. 814 used as denominator $(\mathrm{N}=806)$. 
only a small proportion had completed some higher education $(1.7 \%, 14)$. The proportion of uneducated women was significantly greater in Sokoto $(89.0 \%, 387)$ than Bauchi $(69.4 \%, 263)$ ( $\mathrm{p}<0.001)$. Most mothers were Muslim $(96 \%, 781)$ and married $(98 \%, 798)$. Children's ages ranged from 0-59 months with a mean age of 17.0 months. Of the children, $53.2 \%$ (433) were male and $46.8 \%$ (381) were female. In addition, 15.8\% (129) of mother and child dyads were part of a multifamily household.

\section{Treatment seeking behaviour}

Of children under five with fever in the past two weeks, $76.7 \%$ (624) were brought to treatment. Of those children who were brought to treatment outside of the home (624), 61.5\% (384) followed WHO and NMCP standards to do so promptly, $46.0 \%$ (287) received treatment in the formal sector and $54.0 \%$ (337) received treatment in the informal sector. These behaviours did not differ by state.

Treatment was most often sought at PMVs (45.5\%, $284)$, followed by health facilities $(43.8 \%, 273)$. The remainder sought care at CBHVs, private doctors, traditional practitioners, and other sources (3\% or less of the time, respectively) (Tables 2 \& 3). Treatment location differed by state only for CBHVs, with children accessing them $4.6 \%$ (15) of the time in Sokoto and 1.7\% (5) of the time $(\mathrm{p}=0.04)$ in Bauchi (Table 2).

\section{Testing}

Of children who sought treatment, only $9.8 \%$ (61) received a blood test (Table 2). Children were most likely to receive a blood test if they received treatment at a health facility $(15.0 \%, 41)$, next at a private doctor $(14.3 \%, 2)$, traditional practitioner $(6.7 \%, 1)$, and, last, a PMV $(6.0 \%, 17)$ (Table 3$)$.

Table 2 Care-seeking and treatment patterns for children under five with fever

\begin{tabular}{|c|c|c|c|c|c|c|c|}
\hline & \multicolumn{2}{|c|}{ Bauchi $(N=379)$} & \multicolumn{2}{|c|}{ Sokoto $(N=435)$} & \multicolumn{2}{|c|}{ Total $(\mathrm{N}=814)$} & \multirow[t]{2}{*}{ P-value } \\
\hline & $\mathbf{N}$ & $\%$ & $\mathbf{N}$ & $\%$ & $\mathbf{N}$ & $\%$ & \\
\hline \multicolumn{8}{|l|}{ Sought Treatment } \\
\hline Yes & 299 & $78.9 \%$ & 325 & $74.7 \%$ & 624 & $76.7 \%$ & 0.16 \\
\hline \multirow[t]{2}{*}{ No } & 80 & $21.1 \%$ & 110 & $25.3 \%$ & 190 & $23.3 \%$ & \\
\hline & \multicolumn{2}{|c|}{ Bauchi ( $N=299)$} & \multicolumn{2}{|c|}{ Sokoto $(\mathrm{N}=325)$} & \multicolumn{2}{|c|}{ Total $(\mathrm{N}=624)$} & \\
\hline \multicolumn{8}{|c|}{ Location of first-line treatment or advice sought } \\
\hline Formal & 146 & $48.8 \%$ & 141 & $43.4 \%$ & 287 & $46.0 \%$ & 0.17 \\
\hline Health facility & 138 & $46.2 \%$ & 135 & $41.5 \%$ & 273 & $43.8 \%$ & 0.24 \\
\hline Private doctor & 8 & $2.7 \%$ & 6 & $1.8 \%$ & 14 & $2.2 \%$ & 0.45 \\
\hline Informal & 153 & $51.2 \%$ & 184 & $56.6 \%$ & 337 & $54.0 \%$ & 0.17 \\
\hline PMVs & 136 & $45.5 \%$ & 148 & $45.5 \%$ & 284 & $45.5 \%$ & 1.00 \\
\hline $\mathrm{CBHV}$ & 5 & $1.7 \%$ & 15 & $4.6 \%$ & 20 & $3.2 \%$ & 0.04 \\
\hline Traditional Practitioner & 5 & $1.7 \%$ & 10 & $3.1 \%$ & 15 & $2.4 \%$ & 0.26 \\
\hline Other ${ }^{i}$ & 7 & $2.3 \%$ & 11 & $3.4 \%$ & 18 & $2.9 \%$ & 0.41 \\
\hline \multicolumn{8}{|l|}{ Timing of first-line treatment } \\
\hline Prompt & 192 & $64.2 \%$ & 192 & $59.1 \%$ & 384 & $61.5 \%$ & 0.19 \\
\hline Not Prompt & 107 & $35.8 \%$ & 133 & $40.9 \%$ & 240 & $38.5 \%$ & \\
\hline \multicolumn{8}{|l|}{ Treatment } \\
\hline Received diagnostic blood test & 30 & $10.0 \%$ & 31 & $9.8 \%$ & 61 & $9.8 \%$ & 0.84 \\
\hline Received medication & 245 & $81.9 \%$ & 237 & $72.9 \%$ & 482 & $77.2 \%$ & 0.02 \\
\hline Received non-anti-malarial medication & 131 & $46.4 \%$ & 102 & $35.3 \%$ & 233 & $37.3 \%$ & 0.38 \\
\hline Received anti-malarial & 114 & $38.1 \%$ & 135 & $41.5 \%$ & 249 & $39.9 \%$ & 0.38 \\
\hline Received prompt anti-malarial & 73 & $24.4 \%$ & 92 & $28.3 \%$ & 165 & $26.4 \%$ & 0.27 \\
\hline Received non-ACT anti-malarial & 79 & $28.0 \%$ & 107 & $37.0 \%$ & 186 & $29.8 \%$ & 0.004 \\
\hline Received prompt non-ACT anti-malarial & 51 & $18.1 \%$ & 69 & $21.2 \%$ & 120 & $19.2 \%$ & 0.01 \\
\hline Received ACT & 35 & $11.7 \%$ & 28 & $8.6 \%$ & 63 & $10.1 \%$ & 0.20 \\
\hline Received prompt ACT & 22 & $7.4 \%$ & 23 & $7.1 \%$ & 45 & $7.2 \%$ & 0.89 \\
\hline
\end{tabular}


Table 3 Care-seeking patterns and treatment by location

\begin{tabular}{llllll}
\hline & Prompt treatment & Test done & Anti-malarial given & ACT given & Other medication given \\
\hline Health facility (273) & $58.6 \%(160)$ & $15.0 \%(41)$ & $46.5 \%(127)$ & $14.3 \%(39)$ & $29.3 \%(80)$ \\
Private doctor (14) & $71.4 \%(10)$ & $14.3 \%(2)$ & $35.7 \%(5)$ & $14.3 \%(2)$ & $42.9 \%(6)$ \\
PMV (284) & $64.4 \%(183)$ & $6.0 \%(17)$ & $38.0 \%(108)$ & $7.0 \%(20)$ & $40.8 \%(116)$ \\
CBHV (20) & $45.0 \%(9)$ & $0 \%$ & $25 \%(5)$ & $10.0 \%(2)$ & $45 \%(9)$ \\
Traditional practitioner (15) & $73.3 \%(11)$ & $6.7 \%(1)$ & $13.3 \%(2)$ & $0 \%$ & $66.7 \%(10)$ \\
Other (18) & $61.1 \%(11)$ & $0 \%$ & $11.1 \%(2)$ & $0 \%$ & $66.7 \%(12)$ \\
\hline
\end{tabular}

\section{Medications received}

Of children who received treatment, 39.9\% (249) received an anti-malarial, however $29.8 \%$ (186) received a non-ACT anti-malarial and only $26.4 \%$ (165) received a prompt anti-malarial (Table 2). A child was most likely to receive an anti-malarial if they went to a health facility (46.5\%, 127), next at a PMV $(38 \%, 108)$, private doctor $(35.7 \%, 5), \mathrm{CBHV}(25 \%, 5)$, and traditional practitioner $(13.3 \%, 2)$ (Table 3$)$.

An even smaller proportion of children received a WHO and NCMP recommended ACT $(10.1 \%, 63)$, and only $7.2 \%$ (45) received a prompt ACT (Table 2 ). Children were most likely to receive an ACT (14.3\%) if they received treatment at a health facility (39) or private doctor (2), next from a CBHV $(10.0 \%, 2)$ and then a PMV $(7.0 \%, 20)$ (Table 3, Figure 2). Children were most likely to receive a prompt ACT if they received treatment at a health facility $(10.6 \%, 29)$, next a private doctor $(7.1 \%, 1)$, and last a PMV $(5.3 \%, 15)$ (Figure 2). Treatment results did not differ by child's sex ( $\mathrm{p} \geq 0.17$ ), but did occasionally differ by state $(\mathrm{p}<0.02)$ (Table 2).

\section{Treatment based on national policy/WHO recommended pathway}

Figure 3 illustrates the NMCP/WHO standard treatment pathway. Of children under five who had a fever in the last two weeks (814), 47.2\% (384) sought prompt treatment; of those that sought prompt treatment, $4.8 \%$ (39)

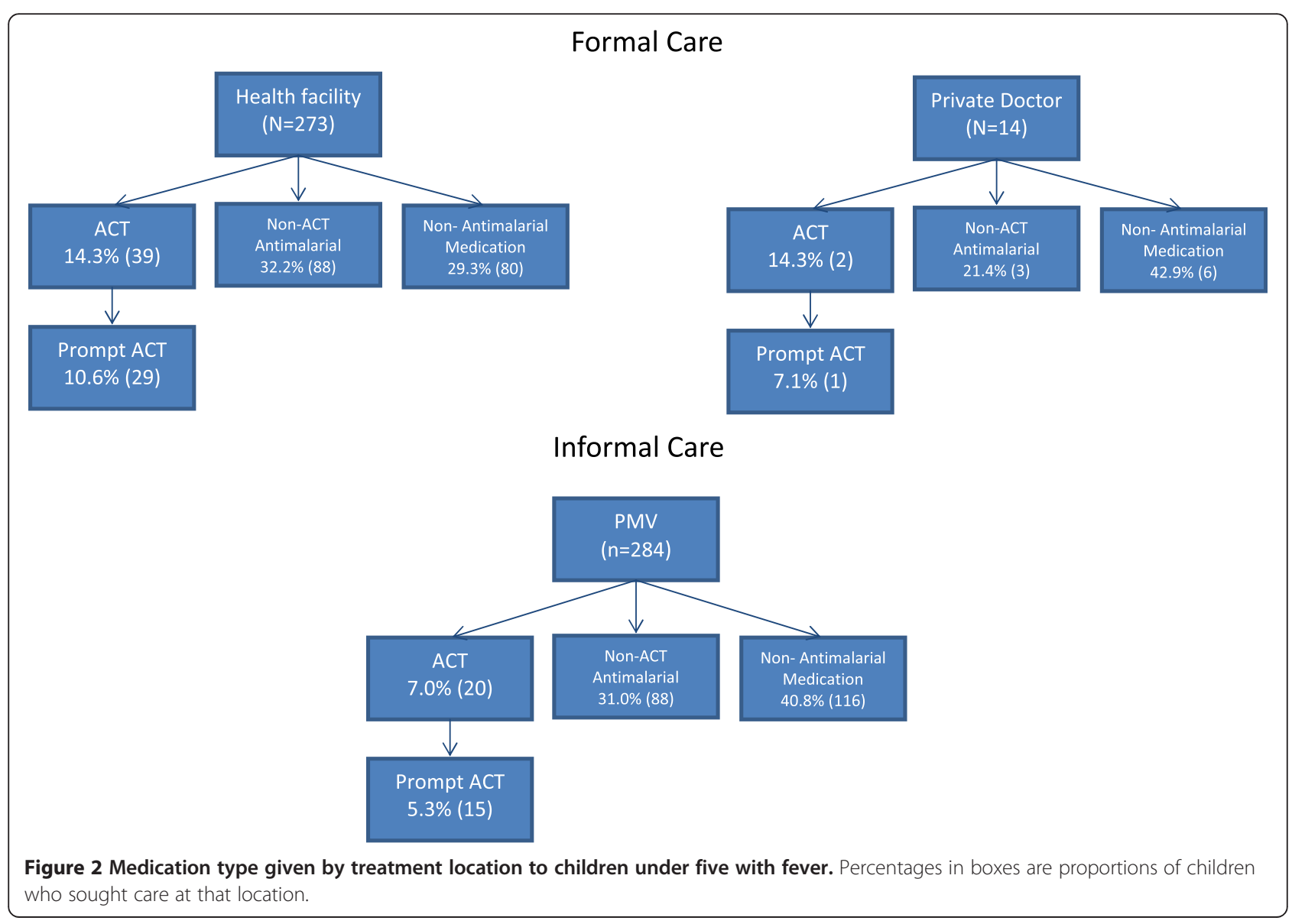




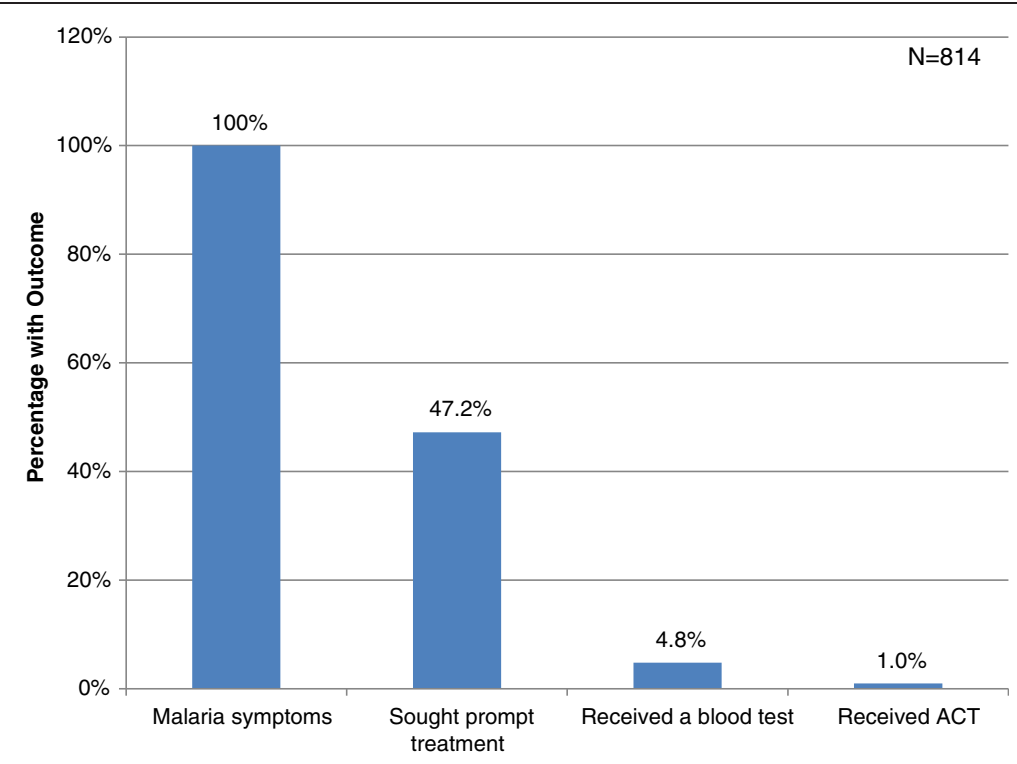

Figure 3 Treatment pathway for children under five with fever who received NMCP/WHO standard care.

of the total sample received a blood test; of those that received a blood test, $1.0 \%$ (8) of the total sample received an ACT.

In addition, Figure 4 illustrates which proportion of children received the NMCP/WHO standard of care stratified by treatment location. Of all locations, health facilities provided the greatest percentage of NMCP/ WHO standard care $(0.9 \%, 7)$. PMVs and traditional practitioners each treated one patient according to the
NMCP/WHO standard, accounting for $0.1 \%$ of children with fever, respectively.

\section{Predictors of treatment seeking}

Table 4 presents the results of the logistic regression created to identify factors that help predict whether a child received treatment outside of the home. The results show that neither state, mother's age, nor child's sex was significantly related to treatment seeking. Child's age

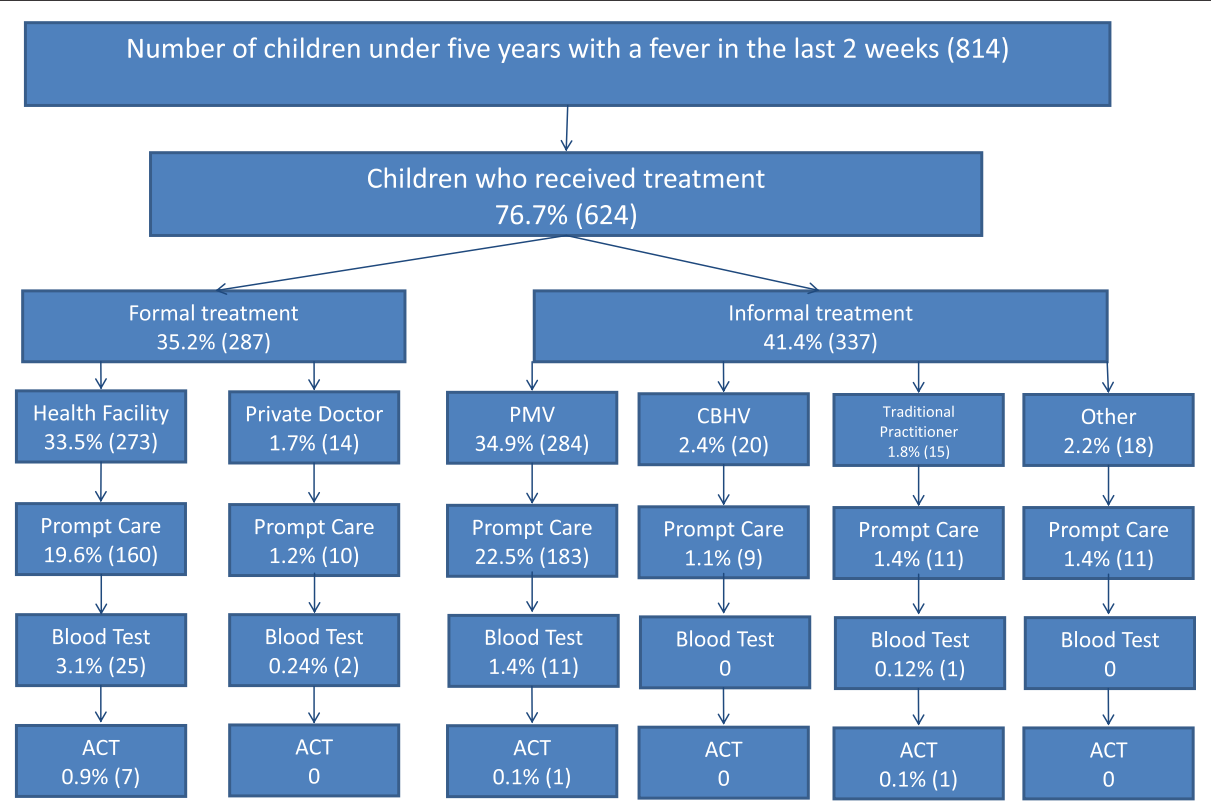

Figure 4 Treatment pathway for children under five with fever who received NMCP/WHO standard care, by location. Percentages in boxes are proportions of all febrile children. 


\begin{tabular}{|c|c|c|c|c|c|c|}
\hline \multirow[b]{2}{*}{ Variable } & \multicolumn{3}{|c|}{$\begin{array}{l}\text { Unadjusted (OR) } \\
\text { Total }\end{array}$} & \multicolumn{3}{|c|}{$\begin{array}{l}\text { Adjusted (OR) } \\
\text { Total }\end{array}$} \\
\hline & $\overline{\mathrm{OR}}$ & $95 \% \mathrm{Cl}$ & $P$ value & $\overline{\mathrm{OR}}$ & $95 \% \mathrm{Cl}$ & $P$ value \\
\hline Mother's age & 1.00 & $0.98,1.03$ & 0.33 & 1.00 & $0.98,1.03$ & 0.84 \\
\hline \multicolumn{7}{|l|}{ Child's age } \\
\hline $0-6$ months & 1.0 & & & 1.0 & & \\
\hline 7-59 months & 1.72 & $1.19,2.48$ & 0.004 & 1.74 & $1.16,3.03$ & 0.003 \\
\hline \multicolumn{7}{|l|}{ Childs sex } \\
\hline Male & 1.0 & & & 1.0 & & \\
\hline Female & 0.87 & $0.63,1.20$ & 0.40 & 0.86 & $0.62,1.20$ & 0.38 \\
\hline \multicolumn{7}{|l|}{ State } \\
\hline Bauchi & 1.0 & & & 1.0 & & \\
\hline Sokoto & 0.79 & $0.57,1.10$ & 0.16 & 0.77 & $0.55,1.07$ & 0.12 \\
\hline
\end{tabular}

Bold values are significant at a $\mathrm{p}<0.05$ level.

was somewhat predictive of treatment seeking, but the pattern was not strictly linear. The clearest indication from the data was that treatment seeking was less likely for children under the age of six months. There was a significantly greater odds of seeking treatment for 7-59 month olds (OR: 1.74, $\mathrm{p}=0.003$ ) compared to $0-6$ month olds, adjusted for mother's age, child's sex, and state.

\section{Discussion}

\section{Care-seeking}

Rates of treatment, prompt treatment, and formal sector treatment in Northern Nigeria are 77\%, 47\%, and 35\% respectively $(\mathrm{N}=814)$. This rate of treatment seeking is consistent with a 2013 study in Nigeria in which $70 \%$ of parents of children under five sought advice or treatment [11]. These rates are also slightly higher than rates discovered in a similar study of malaria treatment in Senegal where $62 \%$ of children under five with fever in the last two weeks received treatment, $40 \%$ received prompt treatment, and $32 \%$ received treatment from the formal sector [15]. However, there is much room for improvement since the malaria treatment seeking rates in Benin, DRC, Madagascar, Uganda, and Zambia are significantly higher ( $83-95 \%)$ [22]. Since only $47 \%$ of caregivers sought prompt care and 35\% sought formal care, future programmatic emphasis may be placed on educating caregivers where and how quickly they need to seek treatment for children under five with fever. Future research in this area may also focus on assessing recognition of malaria symptoms and knowledge of case management strategies among families with children under five years old.

\section{Location of care}

PMVs were found to be the preferred treatment providers, with $46 \%$ of all children under five with fever receiving treatment from this location. This is consistent with the national rate of 46\% [11] and other areas such as the Kabale district in Uganda (53\%) [23]. One reason for this may be that families feel that local private providers are more accessible, are more sensitive to the patients' needs, and spend more time with them than public sector providers $[24,25]$. However, there are key problems with this sector including inappropriate storage [25], knowledge, and dosing of drugs [24,26].

Another downfall of seeking treatment at a PMV is that they are not authorized to administer diagnostic tests [personal communication, Dr. Mohammed Ibrahim]. This was evident by a recent survey that found microscopy completely unavailable at PMVs and RDTs available at $1 \%$ of PMVs [27]. In order to promote all steps in the malaria case management pathway, policy recommendations are to facilitate stocking of and training of staff in the use of RDTs at PMVs. In addition, when RDTs were implemented in the private sector, providers were not knowledgeable in treatment for non-malaria fever, which resulted in treatment with an ACT despite a negative RDT [28]. Therefore, capacity development and quality assurance of this sector is an important piece to improving malaria case management.

Less than half $(44 \%)$ of the parents sought treatment for their children from a health facility, even though health facilities provided the largest proportion of children with recommended case management (Table 3). This rate is actually higher than the national rate of children receiving care at a public facility (35\%) [11].

\section{Use of diagnostic tests}

Despite a national benchmark to promptly test $80 \%$ of children under five with fever [8], in this study, children rarely received a blood test ( $8 \%$ of sample, $10 \%$ of careseeking children). This is lower than the national rate of $11 \%$ [11], and much less than the average rate across 13 sub-Saharan African countries (17\%) [29] and Rwanda (30\%) [30], but higher than the rate of testing in Sierra Leone (1\%) [31].

Although health facilities tested the largest proportion of children in this study (15\%), that proportion is far below the testing rate of $95 \%$ in health facilities in Zambia [32]. In order to bridge the current gap between $\mathrm{NMCP} / \mathrm{WHO}$ standard and current treatment, policies and programmes may focus on making blood tests and ACT more consistently available. A survey done by ACTwatch throughout Nigeria in 2011 showed that microscopic testing was more available than RDTs [27], therefore policies and initiatives to improve diagnostic testing should be consistent with commodity availability 
and acceptability. More specifically, of locations that stocked anti-malarials in the last three months, only $26 \%$ of public health facilities, $37 \%$ of private for profit facilities, and $1 \%$ of PMVs offered any testing services [27]. These stockouts are a key weakness is the ability of facilities to provide diagnostic blood testing consistent with WHO/NMCP standards for malaria case management.

\section{Treatment given}

Of anti-malarials given, 75\% were non-ACT, much higher than the national average of $26 \%$ [11] This is of great concern because malaria is resistant to many anti-malarials in Nigeria [8] and ACT has been the standard of care since 2005 [6]. The rate of standard treatment using prompt $\mathrm{ACT}$ is $7 \%$; higher than the national rate of $4 \%$, but much lower than a study in Tanzania (38\%) [33]. It is likely that a combination of factors influence the low ACT rate. For example, a 2008 study showed only $36 \%$ of PHC health workers in Sokoto had adequate knowledge of malaria case management [34]. In addition, another study showed that only $49 \%$ of public facilities in Nigeria have at least one quality assured first-line dose of ACT [35].

Given the fact that PMVs are the most commonly accessed treatment location, interventions to strengthen their role in malaria case management may result in improved outcomes. In Kenya, an intervention that subsidized ACT for retail outlets, trained retail outlet workers, and strengthened community awareness of case management standards, saw a $25 \%$ increase in ACT treatment for children under five. In addition, a USAID report recommends engaging the private and even informal sector to improve coverage and case management of child illness [24]. Policy and logistics planning should address the lack of training and shortages of essential malaria commodities in recommended and frequently accessed treatment locations.

Given the current stock-outs of ACT and RDTs [18] in Sokoto State, commodity procurement and logistics need to be improved to bridge the gap between available and needed RDTs and ACT. Further research may be needed to understand weaknesses in the supply chain and training of health professionals. Future programmatic and policy activity should focus on strengthening these aspects of health care infrastructure.

\section{Overall and NMCP/WHO standard treatment patterns}

While the majority of caregivers (77\%) seek treatment for children under five presenting with fever, when careseeking pathways are studied, only $1 \%$ of children under five with fever receive treatment according to WHO and Nigeria's NMCP standards: prompt care-seeking, diagnosis with an RDT, and treatment with an ACT. This leaves a staggering discrepancy between the Nigeria NMCP and RBM goal coverage rate of $80 \%$ for prompt
RDT use and subsequent ACT treatment if indicated $[4,6,8]$ and the actual rate among children under five with fever in Northern Nigeria (Figure 3).

Policy and caregiver education strategies are important, but will have limited effect on improving malaria case management if health systems remain weak. In Nigeria, current health system weaknesses include stockouts due to poor procurement and supply chains for malaria commodities in the public health sector, weak delivery of health services in public facilities, lack of necessary and adequately-trained human resources for health, and nearly non-existent diagnostics [4].

The poor state of malaria care in Sokoto and Bauchi could be improved by strengthening national policy and regulatory power in the informal sector. Since informal sector regulation and systems strengthening is often a difficult a lengthy process, incentives such as vouchers or conditional cash transfers may be used to direct patients toward the formal sector until the private and informal sector is can correctly deliver malaria case management.

\section{Predictors of treatment}

Child's age was a significant predictor in the regression for seeking treatment versus not seeking treatment. However, our modeling was limited by the number of variables on the malaria questionnaire. Thus, other factors may be as, or more, predictive of seeking treatment. However, cultural practice could plausibly contribute to the age differences. Several studies have shown that physical confinement is common in Nigerian postpartum practices-often lasting 40 days [36-38]. Confinement has implications for the ability of the mother to seek care for her febrile newborn and may have affected the decreased odds of seeking care for 0-6 months. However, this information may be inconclusive due to the limitations in variables and sample size. Further research should be done to assess factors that facilitate recommended malaria case management.

\section{Limitations}

There are some limitations to using a study based on LQAS methodology to assess care-seeking behaviour of parents. LQAS methodology is designed to cost-effectively compare programme coverage rates with set thresholds to evaluate programme performance. Thus, LQAS surveys typically have relatively small sample sizes (low power) and a relatively limited number of questions. This makes it difficult to perform more complex statistical analyses to establish causal and associative relationships. However, with over 800 respondents, there was good power to assess care-seeking, with a margin of error of only $2-5 \%$ for each question, but a limited number of explanatory variables. 
Similarly, although polygamy is common in the study area, the survey did not assess whether each household was comprised of a polygamous or monogamous family; a study in Ethiopia found that mothers in a monogamous marriage had 3.4 greater odds of seeking treatment for a child under five with fever than mothers in a polygamous marriage [39]. The survey did not specifically ask if medications were procured at location of first line treatment or elsewhere. Thus, it is assumed that the medication was obtained from the first place of treatment. Lastly, the study did not assess the result of the diagnostic blood test. This is a limitation to assessing quality of treatment, since the proportion who received a medication cannot be compared to those who were diagnosed with malaria. However, malaria prevalence rates are so high in these areas, it is assumed the majority of fever cases were malaria.

Several types of bias may have been introduced in the study, but should not affect the conclusions of the analysis. Recall bias is a risk given this was a retrospective crosssectional survey, compounded by the fact that largely uneducated women were asked to recall complex information. However, this bias should be minimal since the maximum time that had to be recalled was two weeks. Misclassification bias was minimized by only classifying a child as receiving treatment if the mother answered both yes to the child receiving a medication and listed what the medication was, even if it was "other" or "unknown".

\section{Conclusions}

Nigeria's NMCP goal coverage rates of $80 \%$ for NMCP and WHO standard malaria case management for children under five with fever in Northern Nigeria are far from being met. Although the best care is provided in health facilities, children are most likely to visit a PMV for first-line treatment of fever. The implementation of national policy change is stunted by drug stock-outs, inadequately trained service providers, and caregivers of children under five with a lack of knowledge of correct malaria treatment. Given the ability to treat a child with malaria differs greatly between facility types, policy and logistics planning should address the shortages of essential malaria commodities in recommended and frequently accessed treatment locations. Particular emphasis should be placed on integrating the private sector into standardized care and educating caregivers on the necessity for testing before treatment and availability of free ACT in public health facilities for the treatment of uncomplicated malaria.

\section{Abbreviations}

ACT: Artemisinin-based combination therapy; AMFm-ACT: Affordable medicine facility-malaria artemisinin combination therapies;

$\mathrm{CBHV}$ : Community- based health volunteer; $\mathrm{FMOH}$ : Federal ministry of health; GPZ: Geopolitical zone; IMR: Infant mortality rate; ITN: Insecticide-treated bed net; LGA: Local Government Area; LQAS: Lot quality assurance sampling; LRT: Likelihood ratio test; MIS: Malaria indicator survey; $\mathrm{MOH}$ : Ministry of health; NMCP: National malaria control programme; OR: Odds ratio; PHC: Primary health clinic; PMV: Patent medicine vendor; RBM: Roll back malaria partnership; RDT: Rapid diagnostic test; RMC: Role model care givers; RMNCH/FP: Reproductive maternal, newborn and child health and family planning; SES: Socio-economic status; TSHIP: Targeted states high impact project; USAID: United States agency for international development; WHO: World Health Organization.

\section{Competing interests}

All authors, with the exception of Dr. Brieger, are employed by JSI R\&T, which is a non-profit company. This involvement does not alter their adherence to all the Malaria Journal policies on sharing data and materials.

\section{Authors' contributions}

KRM participated in the design of the study and performed the statistical analysis and drafted the manuscript. JM participated in the design of the study and carried out extensive planning, review, and revisions to the manuscript. EHC participated in the statistical analysis plan and revisions. WB participated in the design of the study and substantive revisions and feedback on the manuscript. MAl participated in the design of the study and contextual revisions of the manuscript. ZM participated in the design of the study and contextual revisions of the manuscript. $A B$ participated in the design of the study and contextual revisions of the manuscript. WS oversaw the survey design, data collection, participated in the design of the study, and carried out extensive planning, review, and revisions to the manuscript. All authors read and approved the final manuscript.

\section{Acknowledgements}

The authors are grateful to Masduk Abdualkarim, Ringpon Gwanizhi, Toyin Akomolafe, and Akeem Ganiyu for providing assistance in data collection, input, and cleaning. In addition, we would like to acknowledge Solomon Thliza for his assistance with setting the study objectives and providing background contextual information. USAID funded TSHIP and the research. The findings, views and opinions expressed in this article are those of the authors and not of USAID.

\section{Author details}

${ }^{1}$ JSI Research \& Training Institute, Inc., 44 Farnsworth Street, Boston, MA 02210, USA. ${ }^{2}$ Jhpiego, Baltimore, MD, USA. ${ }^{3}$ Targeted States High Impact Project (TSHIP), JSI Research \& Training Institute, Inc., Bauchi, Sokoto, Nigeria.

Received: 27 June 2014 Accepted: 29 October 2014 Published: 21 November 2014

\section{References}

1. WHO: World Malaria Report 2013. Geneva: World Health Organization; 2013.

2. UNICEF: Child Survival and Health - Malaria. New York: United Nations Children's Fund; 2013.

3. UNICEF: Levels \& Trends in Child Mortality. New York: United Nations Children's Fund; 2013.

4. PMI: FY13 Nigeria Malaria Operational Plan. Washington, D.C: President's Malaria Initiative; 2013.

5. NMCP, FMOH, The World Bank: 2010 Malaria Household Survey in Nine States of Nigeria. Abuja: Nigeria's National Malaria Control Programme, Nigeria's Federal Ministry of Health, The World Bank; 2011.

6. RBM: Progress \& Impact Series: Country Reports: Focus on Nigeria. Geneva: Roll Back Malaria Partnership; 2012.

7. WHO: Guidelines for the Treatment of Malaria. 2nd edition. Geneva: World Health Organization; 2010.

8. FMOH: National Guidelines for Diagnosis and Treatment of Malaria. Abuja: Nigeria's Federal Ministry of Health; 2011.

9. FMOH: Strategic Plan 2009-2013: A Road Map for Malaria Control in Nigeria. Abuja: Nigeria's Federal Ministry of Health; 2008.

10. USAID: Nigeria 2008 Demographic and Health Final Report. Rockville: United States Agency for International Development; 2013.

11. USAID: Nigeria 2013 Demographic and Health Final Report. Rockville: United States Agency for International Development; 2013.

12. Welcome MO: The Nigerian health care system: need for integrating adequate medical intelligence and surveillance systems. J Pharm Bioallied Sci 2011, 3:470-478. 
13. FMOH: Integrated Maternal, Newborn, and Child Health Strategy. Abuja: Nigeria's Federal Ministry of Health; 2007.

14. Trape J-F: The public health impact of chloroquine resistance in Africa. Am J Trop Med Hyg 2001, 64(Suppl 1):12-17.

15. Smith LA, Bruce J, Gueye L, Helou A, Diallo R, Gueye B, Jones C, Webster J: From fever to anti-malarial: the treatment-seeking process in rural Senegal. Malar J 2010, 9:333.

16. NPC: National And State Population And Housing Tables: 2006 Census Priority Tables, Volume 1. Abuja: National Population Commission, Nigeria; 2009.

17. Berendes S, Adeyemi O, Oladele EA, Oresanya OB, Okoh F, Valadez JJ: Are patent medicine vendors effective agents in malaria control? Using Lot quality assurance sampling to assess quality of practice in Jigawa, Nigeria. PLoS One 2012, 7:9.

18. TSHIP: Focused Malaria Interventions: Bauchi and Sokoto States. Abuja: Targeted States High Impact Project; 2013.

19. First Bank: Annual Report \& Accounts 2009, Strength \& Stability in Uncertain Times; [http://46.38.182.253/annualreport/2009/company-branch-sokoto.html]

20. Oladele EA, Ormond L, Adeyemi O, Patrick D, Okoh F, Oresanya OB, Valadez JJ: Tracking the quality of care for sick children using lot quality assurance sampling: targeting improvements of health services in Jigawa, Nigeria. PLOS ONE 2012, 7:e44319.

21. Valadez JJ, Weiss W, Leburg C, Davis R: Assessing Community Health Programs: A Participant's Manual and Workbook: Using LQAS for Baseline Survey and Regular Monitoring. St. Albans: Teaching Aids at Low Cost; 2003.

22. Littrell M, Gatakaa H, Evance I, Poyer S, Njogu J, Solomon T, Munroe E, Chapman S, Goodman C, Hanson K, Zinsou C, Akulayi L, Raharinjatovo J, Arogundade E, Buyungo P, Mpasela F, Adjibabi CB, Agbango JA, Ramarosandratana BF, Coker B, Rubahika D, Hamainza B, Shewchuk T, Chavasse $D, O^{\prime}$ Connell KA: Monitoring fever treatment behaviour and equitable access to effective medicines in the context of initiatives to improve ACT access: baseline results and implications for programming in six African countries. Malar J 2011, 10:327.

23. Tumwesigire $S$, Watson $S$ : Health seeking behavior by families of children suspected to have malaria in Kabale: Uganda. Afr Health Sci 2002, 2:94-98.

24. Tawfik Y, Northrup R, Prysor-Jones S: Utilizing the Potential of Formal and Informal Private Practitioners in Child Survival: Situation Analysis and Summary of Promising Interventions. Washington: USAID, Bureau for Africa, Office of Sustainable Development; 2002.

25. Goodman C, Brieger W, Unwin A, Mills A, Meek S, Greer G: Medicine sellers and malaria treatment in sub-Saharan Africa: what do they do and how can their practice be improved? Am J Trop Med Hyg 2007, 77:203-218.

26. Akuse RM, Eseigbe EE, Ahmed A, Brieger WR: Patent medicine sellers: how can they help control childhood malaria? Malar Res Treat 2010, 2010:1-7.

27. PSI: ACTwatch Group \& SFH/Nigeria, Outlet Survey, Nigeria, 2011 Survey Report. Washington DC: Population Services International; 2013.

28. Awor P, Wamani H, Bwire $G$, Jagoe $G$, Peterson S: Private sector drug shops in integrated community case management of malaria, pneumonia, and diarrhea in children in Uganda. Am J Trop Med Hyg 2012, 87:92-96.

29. Johansson EW, Gething PW, Hildenwall H, Mappin B, Petzold M, Peterson SS, Selling KE: Diagnostic testing of pediatric fevers: meta-analysis of 13 national surveys assessing influences of malaria endemicity and source of care on test uptake for febrile children under five years. PLOS One 2014, 18:1-11.

30. USAID: Rwanda 2013 Malaria Indicator Survey. Rockville: United States Agency for International Development; 2013.

31. USAID: Sierra Leone 2013 Malaria Indicator Survey. Rockville: United States Agency for International Development; 2013.

32. Manyando C, Njunju EM, Chileshe J, Siziya S, Shiff C: Rapid diagnostic tests for malaria and health workers' adherence to test results at health facilities in Zambia. Malar J 2014, 13:166.

33. Simba DO, Warsame M, Kakoko D, Mrango Z, Tomson G, Premji Z, Petzold $\mathrm{M}$ : Who gets prompt access to artemisinin-based combination therapy? A prospective community-based study in children from rural Kilosa, Tanzania. PLoS One 2010, 5:1-8.

34. Umar AS, Abdulkareem O०: Malaria case management among primary health care workers in Sokoto. Niger Postgrad Med J 2008, 15:76-81.

35. O'Connell KA, Gatakaa H, Poyer S, Njogu J, Evance I, Munroe E, Solomon T, Goodman C, Hanson K, Zinsou C, Akulayi L, Raharinjatovo J, Arogundade E, Buyungo P, Mpasela F, Adjibabi CB, Agbango JA, Ramarosandratana BF, Coker B, Rubahika D, Hamainza B, Chapman S, Shewchuk T, Chavasse D:
Got ACTs? Availability, price, market share and provider knowledge of anti-malarial medicines in public and private sector outlets in six malaria-endemic countries. Malar J 2011, 10:326.

36. Dike P: Birth practices of Nigerian women: a literature review. Afr J Midwifery Womens Health 2013, 7:39-48.

37. Iliyasu Z, Kabir M, Galadanci HS, Abubakar IS, Salihu HM, Aliyu MH: Postpartum beliefs and practices in Danbare village, Northern Nigeria. J Obstet Gynaecol 2006, 26:211-215.

38. Eberhard-Gran M, Garthus-Niegel S, Garthus-Niegel K, Eskild A: Postnatal care: a cross-cultural and historical perspective. Arch Womens Ment Health 2010, 13:459-466.

39. Getahun A, Deribe K, Deribew A: Determinants of delay in malaria treatment-seeking behaviour for under-five children in south-west Ethiopia: a case control study. Malar J 2010, 9:320.

doi:10.1186/1475-2875-13-447

Cite this article as: Millar et al:: Patterns and predictors of malaria careseeking, diagnostic testing, and artemisinin-based combination therapy for children under five with fever in Northern Nigeria: a cross-sectional study. Malaria Journal 2014 13:447.

\section{Submit your next manuscript to BioMed Central and take full advantage of:}

- Convenient online submission

- Thorough peer review

- No space constraints or color figure charges

- Immediate publication on acceptance

- Inclusion in PubMed, CAS, Scopus and Google Scholar

- Research which is freely available for redistribution

Submit your manuscript at www.biomedcentral.com/submit
C) Biomed Central 